\title{
Health Equity and Universal Provision in Norway: A Case Study
}

\author{
Lydia Mehrara* \\ Department of Social Studies \\ Faculty of Social Sciences \\ University of Stavanger \\ Email: lydia.mehrara@nord.no
}

${ }^{*}$ corresponding author

\section{Dr. Susan Young}

Social Policy Practice and Research Consortium

Faculty of Health and Medical Science

The University of Western Australia

Email: susan.young@uwa.edu.au

\begin{abstract}
This article reports on a qualitative study undertaken to explore the policy-practice nexus of health policy in Norway in relation to the provision and delivery of maternal health services to migrant women. The research used a case study approach focusing on a particular programme which provided maternal health services to migrant women and collected data through review and analysis of policy documentation, observation of this programme, and discussions with people responsible for implementing health policy. While Norway is well known for its universal policy principles, which in the main enable good access to services, the case study indicated that there are some limitations in policy and practice. We use the principle of proportionate universalism to comment on and make recommendations for policy makers and practitioners in this area, to better attend to the principle of equity in service access and usage. The article provides an overview of the Norwegian health policy systems, structures and provisions; describes the service provision from a specific programme providing maternal health services to migrant women in Stavanger, Norway; and concludes with some recommendations which emerge from the findings.
\end{abstract}

Keywords: Maternal Health, Migrant Women, Migrant Health,

Social Policy, Social Work, Norway, WPR Framework 


\section{Background and Introduction}

This study reports on data from a study conducted in 2017 to explore the application of a universalist provision of maternal health services to migrant women. This is an important area of research because migration not only poses new challenges for the welfare state in its delivery of health services, it also has consequences for the health of the migrants.

Health policy in Norway derives from its social democratic principles with the assumption that equality of provision equals equality of access and thereby of outcomes. However, this thinking is problematic. Although Norway has not experienced the same magnitude of people movements as some of its neighbouring countries, non-western migration to Norway has increased (Tronstad, Nygaard, \& Bask, 2018, p. 16). The consequent changes in diversity have meant institutions in Norway have had to consider how they will meet different cultural needs (Regjeringen, 2017; Tronstad et al., 2018).

To avoid misconceptions, in this article the term 'migrant' includes both documented and undocumented women as for certain maternal health provisions undocumented women may access some pregnancy-related services. Access to these services are designated as 'absolutely necessary' (Kvamme \& Ytrehus, 2015, p. 3), and as such constitute emergency treatment rather than the types of services women may choose to or be recommended to access, such as the programme to be described later in this paper. However, it may well be that some of the attendees of the programme were undocumented.

A local municipality-based programme offering health services and resources to migrants was used as a case study to explore the application of health policy in the area of migrant maternal health. Observations of the programme were carried out over a period of four months in early 2017; discussions were held with policy makers, programme directors and managers and policy documentation were reviewed. The structure of investigation was guided by the two principal research questions, listed in the methods section, which concern Norwegian health policy's considerations and provisions of maternal health services for migrant women. The findings and discussions were set within the larger Norwegian health policy context applying a critical policy analysis framework (Bacchi, 2009) to both analyse the findings around the research questions, and articulate suggestions for future policy research and policy development. The study concluded that, despite the social democratic intent of ensuring equality through equal provision, the implementation of the 
policy faced a number of challenges which needed to be addressed to ensure equality of access. It raised the issue of the equity-equality nexus and prompted a question for policy: to what extent can equality tolerate diversity, or, to re-phrase it, what unequal measures are necessary to achieve equity and what does this mean for the social democratic ideal? Reflecting on these questions, this article presents the argument that a targeted or proportional universalism (Carey, Crammond, \& De Leeuw, 2015) is necessary to address the different needs of diverse groups of people, such as migrant women, at the same time as affording them equal or universal access and benefit.

This article begins by providing context to the issue being studied by introducing the significance of migration to maternal health and goes on to describe the current migration circumstances in Norway and Norway's health policy. An account of the methodology used, and description of the case example in the findings section follows. The subsequent discussion examines the Norwegian policy position in maintaining its type of Welfare State in relation to health, by considering the experiences of a localised service for migrant women. The paper concludes with some reflections on targeted or proportionate universalism as an aspect of a social democratic system which could contribute to both local and national policy development.

\section{Migration and Maternal Health}

Maternal care and women's right to their reproductive health for legal migrants in most European countries has been found to present challenges for the countries' service delivery systems, and have implications for the health outcomes of migrant women. Research reports challenges for service delivery systems, health outcomes, help seeking and differential access patterns (Darj \& Lindmark, 2002; Dejin-Karlsson \& Östergren, 2004; Ny, 2007; Rechel et al., 2011). Migration further increases the vulnerability of pregnant women and their new-born children, with Reeske and Razum (2011, p. 139) maintaining that "health differentials during pregnancy, birth, the neonatal period and the first year of life are sensitive indicators of social inequalities".

Multiple studies illustrate the concerns. Utilization of prenatal and antenatal care by migrant women is less frequent in comparison to non-migrant women (Nørredam \& Krasnik, 2011); they begin antenatal visits later in their pregnancy; and make fewer appointments (Reeske \& Razum, 2011). Induced abortions among non-western migrants are greater than non-migrant women, which may indicate lack of knowledge of preventative measures in reproductive health (Nørredam \& Krasnik, 2011). Other disparities exist in 
such unfavourable birth outcomes as: still births; low birth weights; preterm birth, congenital defects or malformations; and an increased risk of maternal and infant mortality (Reeske \& Razum, 2011). There is a growing recognition among these studies and others that the cause of these disparities go beyond the legal and physical access to health services, and in fact suggest a problem of knowledge, accessibility, appropriateness, or quality for migrant women.

While studies have examined the health concerns and outcomes for migrant women, very little research appears to have explored how the more implicit and informal social determinants, such as ethnicity and culture linked to migrant women's health, contribute to positive or negative outcomes, or whether these have been addressed in health policy. This is particularly the case in Norway where there appear to be no studies conducted on the effects of health policy on migrant women's health.

\section{International Immigration in the Norwegian Context}

Up until the late 1970s migrants comprised a very small percentage of the Norwegian population. But Norway's immigrant intake has changed from the latter part of the Twentieth Century to accommodate refugee and asylum seeker arrivals as well as the more common migration for work and education purposes. Persons with immigrant backgrounds constituted $16.8 \%$ of Norway's total $(5,258,317)$ population $(S S B, 2017 b)$ as of January $1^{\text {st }} 2017$, comprising 724, 987 immigrants and 158,764 Norwegian-born to immigrants: a total of 883,751 . Approximately $50 \%$ of this population is aged between 20 40 years of age, and less than $9 \%$ over 60 years of age, making it younger than the average population (SSB, 2017c). A significant number of this young migrant population are women of average childbearing age (20-44 years old). The source countries of more than half a million immigrants in 2017 were from Asian, Latin American and African countries as well as other non-European countries (Tronstad et al., 2018, p. 16). The health systems in these areas differ markedly from that in Norway, along with very different cultural beliefs and behaviours in relation to maternal health.

Settlement patterns show Oslo, the capital, and its surrounding regions to have the highest concentration of migrants, with Rogaland county on Norway's south-west coast having the fourth highest in January 2017 (SSB, 2017c).

Stavanger, the location of this study, is one of the larger municipalities in Rogaland county. Moreover, Stavanger is known as the oil capital of Norway, 
and has "percentage-wise, the largest foreign population" in the country (Gjerstad, Johannessen, Nødland, Skeie, \& Vedøy, 2016 p. 172). The migrant population is largely an even distribution between work migrants, their families, refugees and asylum seekers (Gjerstad et al., 2016). As of January $1^{\text {st }} 2017$, there were 19,791 women of immigrant and Norwegian-born to migrant background, who were of childbearing age (20-44 years of age) living in Rogaland county (SSB, 2017a). This represents more than half the entire $(37,985)$ female migrant population in the region (SSB, 2017a). These features of the municipality made it a strategically advantageous location to carry out a policy analysis on migrant maternal health services.

\section{Norwegian Health Policy System}

The foundations of Norway's social democratic welfare state rest on the principles of community, equality, mutual respect and trust (Esping-Andersen, 1996) using progressive taxation to reduce economic inequality and to finance generous public services (Pierson \& Leimgruber, 2010). Its principle of universalism, offering all citizens equal access to services as a national priority (Kangas \& Kvist, 2012; Ringard, Sagan, Saunes, \& Lindahl, 2013), results in lower levels of inequality between the poor and the rich, and between men and women (Kangas \& Kvist, 2012) than in other jurisdictions. Such measures and the commitment to "redistributive policies (both economic and social) and full-employment policies, such as the social democratic parties, are generally more successful in improving the health of populations" (Navarro \& Shi, 2001 p. 181). Thus, Norway's low levels of inequality, higher satisfaction with life, and the population's overall high quality of health has been attributed to the country's comprehensive and accessible health and welfare programs (Kangas \& Kvist, 2012).

Norway operates a decentralised system for service provision as illustrated in Figure 1. 
Figure 1 - TEGRA as a Health Service Provider

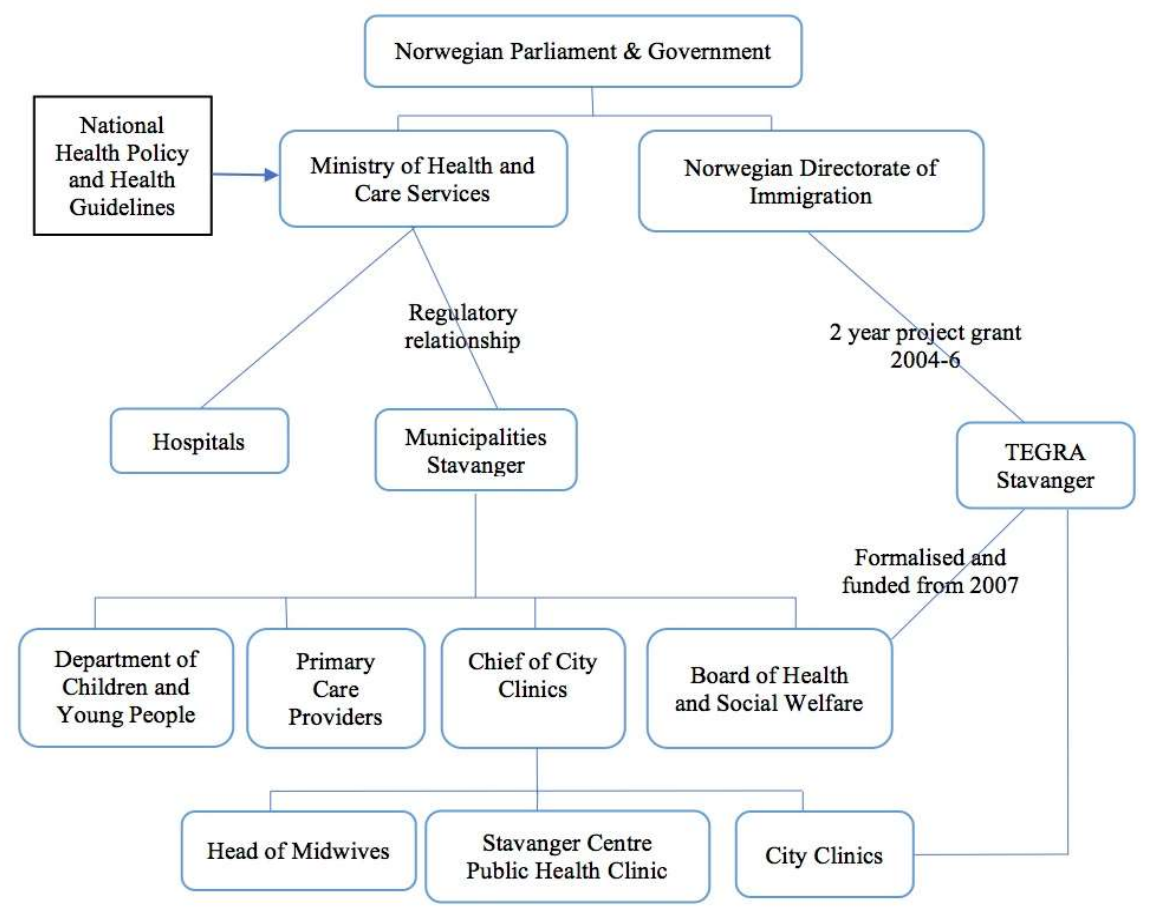

Adapted from Figure 2.1 in Ringard et al. (2013, p. 17)

An intricate set of relationships exists. Primary health care and hospital related services are separate from but responsible to the Ministry of Health, and do not indicate systematic collaborative relationships or partnerships. Furthermore, the decentralised system assumes that primary service provision operates most efficiently at the most local level possible and is therefore the responsibility of municipalities.

In Stavanger, maternal health services are offered by three main bodies: physicians including General Practitioners and Gynaecologists; primary care centres; and the Stavanger Universitetssjukehus hospital. The municipality of Stavanger has six public health clinics called the 'Helsestasjon' that offer free primary health services to families and children living across the city's seven boroughs. As indicated in Figure 1, potentially, unless there are specific initiatives, these services can and do operate independently from each other. All services are provided with no specific cultural or ethnic considerations, although the high level of migrants is acknowledged through the availability of interpreter services (Helsenorge, 2015).

A health programme called TEGRA, which stands for 'inTEGRAtion', is run by the Stavanger municipality. This program offers a range of maternal health workshops and other activities to migrant women and their families. This 
program was selected as the case study for this research. The detailed rationale for its selection as the site of study is presented in the subsequent Methods section, while a full description of TEGRA is provided in the Findings section.

\section{Methods}

Anecdotal narratives suggested that migrant women were not able to satisfactorily access some of the maternal health services which were part of Norway's universal health system. Therefore, this research used an exploratory process to examine the nexus between policy and practice in Norway in relation to the provision and delivery of maternal health services to migrant women. Having been conducted within a program setting certain time frames for the scope and design of the research, a case study approach was employed to provide as detailed an account as possible of one example of health provision to migrant mothers, in order to explore the application of Norwegian health policy. The research questions that enabled this exploration were:

How does Norwegian health policy provide maternal health services to migrant women?

How have these policies enabled accessibility and acceptability of maternal health services to migrant women?

\section{Design}

An instrumental case study approach (Stake 1995; as cited in Baxter \& Jack, 2008, p. 549) was employed as the main focus was health policy and practice rather than the specific situation itself. As a research approach, instrumental case studies explore a complex phenomenon within its context, by way of gathering and interpreting data from various sources to answer "how" and "why" questions (Baxter \& Jack, 2008, p. 545) allowing for the "multiple facets of the phenomenon to be revealed" (Baxter \& Jack, 2008, p. 543). Thus, they provide for a more holistic understanding, and strengthen findings through data triangulation, enhancing their credibility and trustworthiness.

A case study design was selected for its ability to identify aspects of a phenomenon for further research as is fitting with an exploratory approach. While recognizing that findings could not be generalized, it was considered that examining a specific example of practice as illustration of policy could 
indicate areas worthy of further investigation. The programme TEGRA was selected for exploration as Stavanger is in a region with one of the largest migrant populations in the country and could be expected to provide useful information and indicate questions for future research. Further, TEGRA was selected as the site for the case study as compared to one of Stavanger's health clinics because of its extended services beyond pre- and post-natal group workshops and its customization for migrant women.

\section{Data Sources and Collection}

As the policy-practice nexus was the main focus for the study, policy documentation formed the main data source. These were supplemented by discussions with policy makers, programme managers and other health professionals in Stavanger. National and local policy documents provided information about the overall health policy principles and structures and the policy framework within which TEGRA and the municipality operated. Unstructured discussions were held with local policy makers and other health professionals, in which they were asked to describe how health policy was implemented and enacted in Stavanger. In keeping with an exploratory study, these descriptions filled in the detail of what is usually summarised in official documents and provided some history to health provisions and reasons for establishing TEGRA.

Observations of workshops and activities run by TEGRA provided ancillary data, which were considered in light of the policy documentation and comments from policy makers from the Board of Health and Social Welfare. The researcher attended four workshops and group activities at TEGRA during a four-month period with the permission of the health officials and TEGRA organisers. While not a participant, the researcher did interact with the programme leaders and participants who were informed about the study, and all of whom agreed to her presence. Notes were taken of the activities and information provided. No structured interviews or discussions were conducted with the workshop participants and organisers, and any conversations held were for the purposes of clarifying or confirming information. No participant or organiser was cited or quoted in this study. Another study may well wish to interview participants for their feedback on the appropriateness and effectiveness of the workshops and activities, and this would add to further knowledge. 
Trustworthiness of the data was addressed through the multiple sources of data as well as through researcher and supervisor reflection. Being mindful that all researchers in qualitative research affect the research, the researcher's position as a female was noted as potentially influencing the research. These discussions explored the likely influences of her positionality on the findings which were scrutinised for any examples of such influence and revised accordingly.

\section{Analysis}

Bacchi's (2009) What's the Problem Represented to Be? (WPR) framework consisting of six critical questions, as presented below in Figure 2, was adopted as the analytical framework for the study and hence applied to all data: policy documents, discussions and observations. Founded on the four traditions of social constructionism, post-structuralism, feminism and governmentality, Bacchi's model aims to 'work backwards' and deconstruct any public policy to deduce implicit discourses underlining the construction and representation of 'problems'(Bacchi, 2012). The WPR was used both as an analytical tool, as well as a frame for how the analysis is presented and developed in the Discussion section. This approach to the presentation of discussions is critical, because the chronology imposed by the framework is an integral part of the process of the policy analysis in this report. Therefore, the aim in applying this analytical framework to the case study and other data was to critically review the connections between the policy and TEGRA's services, as an example of a programme for maternal migrant health. 
Figure 2 - The six questions of Bacchi's (2009, p. 48) 'What's the problem represented to be?' (WPR) framework for policy discourse analysis

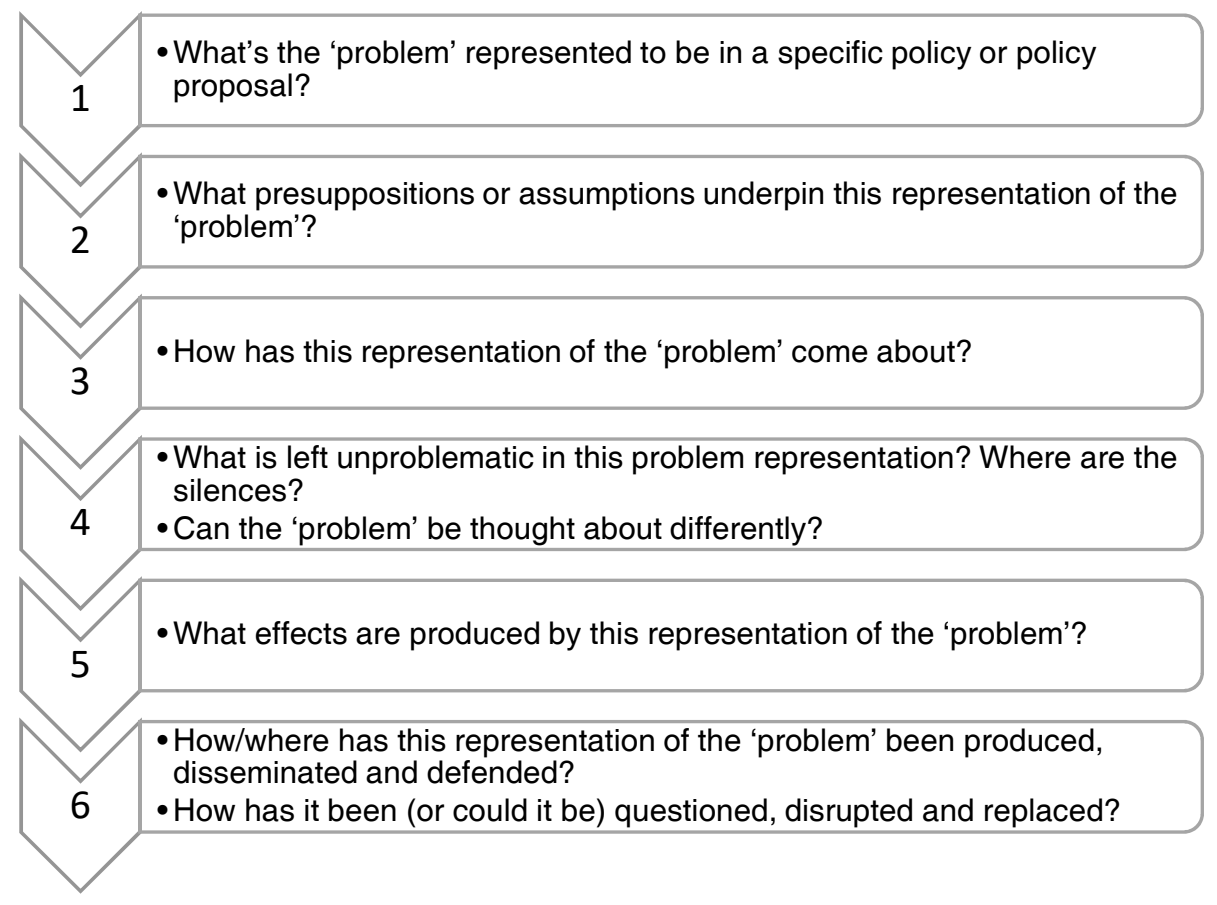

\section{Ethics}

The Norwegian centre for research data (NSD) did not require ethics approval be sought for this project. Nevertheless, ethical practice applied in the informing of all contacts (advisors and health care personnel) about the purpose and significance of this study and in ensuring all data were treated with sensitivity and integrity, and importantly that all people associated with TEGRA were treated with respect and dignity.

A visual illustration of the research design is presented in Figure 3. 
Figure 3 - Illustration of Research Design

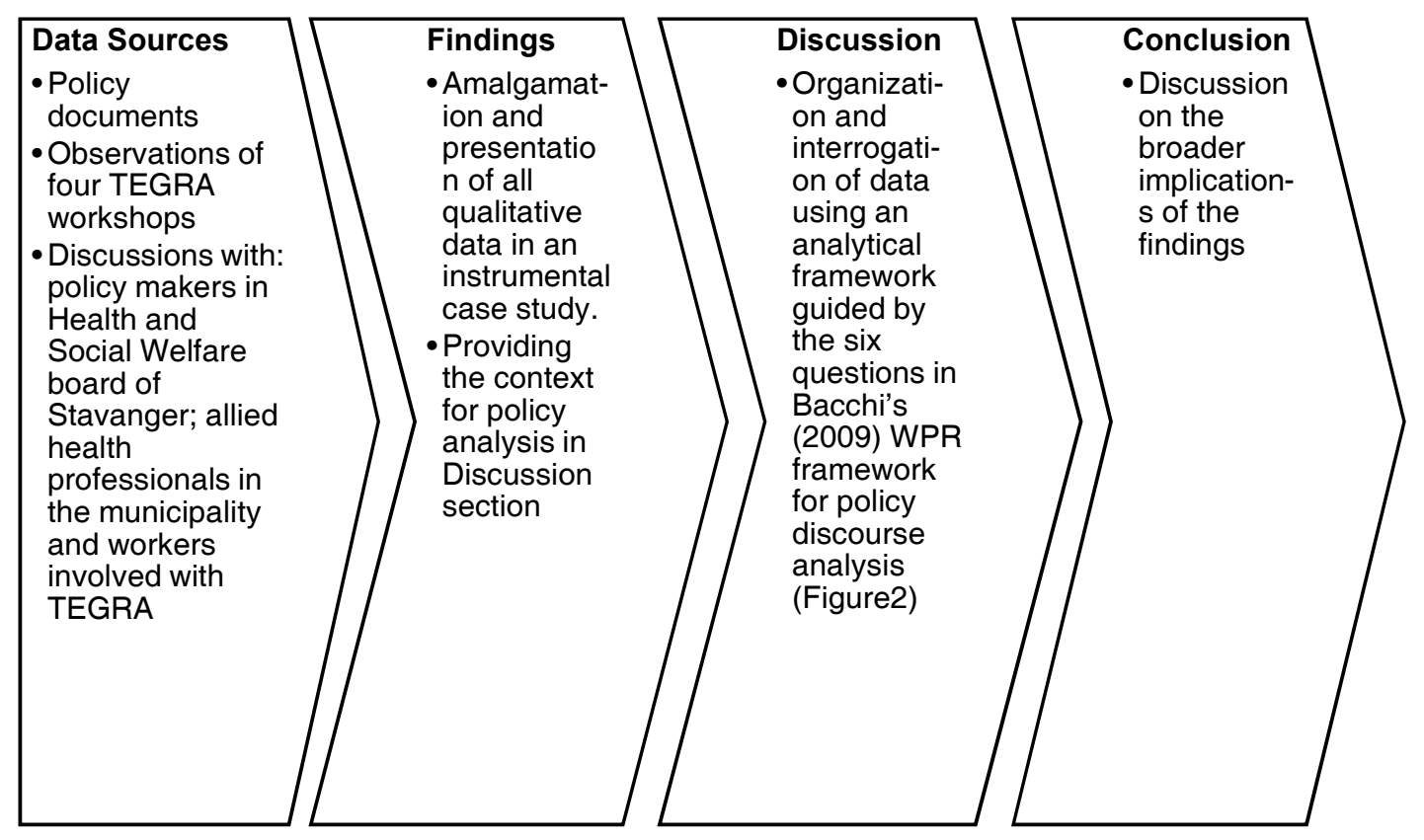

\section{Findings}

TEGRA, a Case Example Addressing Migrant Maternal Health in Stavanger

This section offers a presentation of the case study, and in doing so the context for the analysis in the Discussion section. To begin, Figure 1 locates TEGRA as a municipally funded health programme in the Stavanger Kommune.

\section{History of TEGRA}

TEGRA's initial focus was to contribute to the national action plans against Female Genital Mutilation (FGM) in the early 2000s as part of the O.K. initiative (translated as Care and Knowledge against Female Circumcision) (Norwegian Ministries, 2008). Furthermore, in line with O.K's initiative, TEGRA aimed to increase the cultural competency of healthcare professionals and other service providers working with immigrant women and families, especially dealing with sensitive topics such as FGM. TEGRA's culturally diverse team highlighted the importance of multicultural understanding in effectively addressing sensitive health issues such as FGM prevention practice (Helsesøstre, 2007). 
Commencing in December 2002 at the central health clinic in Stavanger (Stavanger Kommune, 2016a; Sykepleierforbund, 2014), TEGRA focuses on working with immigrant families, in particular with women and children to prevent their social isolation. The program operated mostly through volunteer work (Helsesøstre, 2007), until it was recognized by the UDI (The Norwegian Directorate of Immigration) in 2004 and received funding for two years. In 2007, after a year's pause (Helsesøstre, 2007), the project received formal recognition from the municipality and was integrated into the public health system (Sykepleierforbund, 2014).

\section{TEGRA Today}

In addition to working on the national action plans against FGM in Norway, TEGRA also organizes free childbirth preparation (Fødselsforberedende kurs) and postnatal (Barselgrupper) group workshops for immigrant families living in Stavanger. The workshops are held several times throughout the year, and families can request to have interpreters free of charge (Stavanger Kommune, 2016b). In 2016, there were 12 pre-natal groups, with a total of 172 pregnant women from 56 different nationalities; and 8 post-natal groups, with a total of 104 families from 46 different nationalities who participated.

TEGRA is one of few providers of maternal health services in Stavanger, however, it is the only provider that specialises in migrant women's health. Nevertheless, the intention of all maternal health service providers is to ensure that all mothers have equal access to maternal services, and information to obtain optimal pregnancy outcomes. The Norwegian Directorate for Health (n.d) strongly recommends that all municipal health centres offer prospective and new parents the opportunity to take part in group consultations. The purpose of a group-based initiative is to enable parents in the same situation to share their knowledge and experience about childcare and parenting with each other, and to also have the chance to meet and create a social network with other parents in their community. All the health clinics in Stavanger offer these post-natal group workshops.

\section{Maternal Health Services and TEGRA}

In addition to having a midwife and a GP, every pregnant woman is assigned a helsesøster (health nurse) or health visitor from their local public health clinic. After report of delivery, the woman's health visitor pays her a single home visit during which the mother is provided with information about the post-natal group courses (Barselgrupper) at her local health clinic. If she has 
a migrant background and is not fluent in Norwegian, the health visitor also provides her with information about TEGRA at the central city health clinic. Since these courses are voluntary, it is the mother's responsibility to make an appointment and register her interest for attending either one of the courses.

The post-natal group courses offered at the city's six clinics aim to enhance maternal and child health and have existed long before TEGRA was developed. However, their accessibility to migrant women who did not speak Norwegian has been limited, and hence migrant women's attendance at the courses has been very low. Women who wished to participate but did not speak Norwegian had the option of purchasing private courses in their language for a fee. This is not a feasible option for many, and as a consequence of accessibility, many migrant women have not been able to benefit from this service.

\section{The Workshops}

TEGRA's operations differ from and supplement the city-wide programs. They are targeted at migrant women, and provide information about the Norwegian health care systems as well as answer questions for people unfamiliar with these ways of working. Common questions concern the prominent role of midwives compared to gynaecologists, and different postdelivery practices, such as being discharged after three days and walking soon after birth; practices that differ from those in some other countries. Other information is intended to inculcate migrant women into the Norwegian system and approaches. These include discouraging women from opting for caesarean delivery and emphasizing the benefits of natural birth using scientific evidence. TEGRA staff have found that a significantly high number of migrant women prefer caesarean delivery based on their cultural norms and the stigma against natural birth in their home countries. Breastfeeding is another practice some migrant women reject, and the role of men in attending to infants is also a new concept to some. These differences are in part cultural and in part reflect western market and other influences in non-western countries, such as perceptions that formula milk is preferable to breast milk (Muula, 2007; Stevens, Patrick, \& Pickler, 2009), and surgical procedures preferable to natural births. Such cultural norms which are passed down the generations are contrary to those of the health system in the host country and can create division and resentment if handled without sensitivity.

\section{Cultural Sensitivity}


TEGRA's organisers intend to be as culturally inclusive and responsive as possible. While genuinely attempting to provide useful information in engaging ways, presenters at the workshops would sometimes lapse into generalities. Some examples included characterising the help provided from TEGRA as akin to the 'watering wells' used in some countries for women to gather and exchange information and provide support, or disregarding specific cultural prohibitions, such as recommending the use of pork liver pâté ('leverpostei' in Norwegian) as infant food to an audience inclusive of Muslim women. Generalising can become stereotyping, not all migrant women have experience of 'watering wells', and additional options to pork liver pâté could be recommended to acknowledge cultural diets. Other potential but unintended cultural offences could occur such as illustrated by a demonstration of breastfeeding techniques via video and then repeated by a nurse using props being performed in front of male class attendants. At this workshop, it was evident that some men were uncomfortable as they frequently glanced away during this part of the course. Given the diverse range of nationalities and ethnicities of attendees, being able to provide culturally specific and appropriate information is a challenge requiring detailed knowledge and understanding.

\section{Language}

In addition to the range of cultural and religious backgrounds of attendees, language is another consideration, which is recognised through the free provision of interpreters on request. Observation of this in action found the courses to be facilitated by PowerPoint presentations, videos, handouts, and props with the presenters pausing regularly to allow for interpreters to translate the content and allow for questions to be asked and thoughts to be shared. Although all Stavanger health clinics offer post-natal workshops in Norwegian, Sykepleierforbund (2014) suggests that immigrant women have a much lower turn up rate to the city-wide program. Several factors such as language barriers and lack of knowledge have been suggested as contributing factors for the difference (Sykepleierforbund, 2014). It may be that the attendance is more regular and that more women are attracted to TEGRA than in the city-wide programme because of free access to interpreters. However, this has its limits. It would be impractical to have potentially up to 57 different interpreters in the classes, even should trained interpreters be available in Stavanger to cover all language groups. Furthermore, a common practice of employing male interpreters to work in the culturally sensitive areas 
of childbirth, breast feeding and other gynaecological matters for some groups could present barriers to participation.

\section{Timing and Location}

There are other limitations which face the TEGRA organisers including the timetabling of the courses and its location. Morning and afternoon classes on one day a week do not readily attract those workers on shift work, a common occupation condition for migrant workers making male partner attendance difficult. The central city location is convenient for public transport, but sometimes lengthy journeys, and having to travel with other children create unneeded barriers.

\section{Accessibility and Availability}

A major potential barrier is that of the lack of connection between the hospitals, clinics, health visitors and midwives. TEGRA is the only programme that covers all the topics associated with pre- and post-natal information over a period of time, which enables women to ask the questions as they emerge from their experiences or gestational changes. If they miss or do not attend the courses, they have to make special arrangements to call the clinics, ask their midwives or health visitor, or the hospitals after birth.

Figure 1 illustrates the lack of organisational affiliation between the state-run hospitals and the primary care centres in Norway. Subsequently, hospitalbased midwives and other care providers are not associated with municipally run programs such as TEGRA. As a result, the quality of and sensitivity to culturally relevant care, and level of awareness is likely to vary across these institutions, because the care providers are trained according to different guidelines. Although examples cited above indicate that staff at TEGRA are not fully conversant with culturally appropriate protocols, it is possible that larger institutional organisations such as hospitals may be less so, despite the provision of interpreter services (Helsenorge, 2015). Accessibility to information about TEGRA suffers from a similar restriction. Women can find out about TEGRA if their practitioners (GPs or Midwives) inform them about it. Otherwise, information available on the municipality's website is restricted to a very short outline about the course and instructions on how to register, again only in Norwegian and English.

Norwegian Norms 
Finally, the content presented in TEGRA has been selected and organized by Norwegian practitioners according to Norwegian notions of good practice. In other words, the program is founded upon a mono-cultural understanding of maternal health needs, which reflects Norwegian norms, mores and expectations. The focus is not on addressing any specific issues affecting migrant women or on making the Norwegian course content more culturally sensitive to the needs of women from diverse backgrounds.

\section{Discussion}

In this section, the six questions from Bacchi's (2009) "What's the Problem Represented to be?" (WPR) critical policy analysis framework (Figure 2) were used to tease out the policy implications of the TEGRA example of providing maternal health services to migrant women in Norway.

First Two Questions -the 'Problem' and its Presuppositions

One of the initial challenges to using this framework was presented by the first two questions: What's the problem represented to be? and What are the underpinning assumptions? In other applications of this framework, for example drug policy (Lancaster \& Ritter, 2014), how drug use is constructed politically and through language, reveals much about ideology, partisanship, moral judgements, how the problem is conceptualised, is it a criminal justice or health matter and so on. In the case of the provision of health services in a universalist state such as Norway, the 'problem' is that this is not considered to be a problem. Here, everyone, with very few exceptions, has access to health services. The 'problem' becomes how the service provision itself is represented, or, how accessible are the services, and is that accessibility equal? On the surface, all women have equal access to services. But, as has been shown in the findings, the way services are provided mean that barriers exist in the form of cultural appropriateness, sensitivity and relevance.

The What's the Problem Represented to be framework is usually applied to policy texts and subject to critical analysis. Here health policy documents were used, supplemented by observations of the TEGRA programme and discussions with policy practitioners. Social activities such as described in the case study, are also considered to be text (Ricoeur, 1971) and so are also able to be included in Bacchi's framework. The observed and dialogic data were able to add a qualitative depth to the written policy documentation. While the 'problem' of access to the provision of maternal health services by migrant women is not represented as such in the policy documents, observational and 
discursive data indicate TEGRA's organisers considered it to be so, hence the development of the programme.

\section{Third Question - a Historical Overview}

Historically too, in reference to Bacchi's (2009) third question concerning the historical genesis of the issue (Figure 2), TEGRA's provision of its current services emerged from a national culturally specific policy to act against the practice of Female Genital Mutilation (FGM). Where FGM certainly was constructed nationally as a problem, even though, as Braun (2009) explores, as a problem it is variously represented, being able to access maternal health services was not. Hence the program was originally established and was funded to work with FGM. It was later that TEGRA organisers themselves constructed the 'problem' of migrant women's access to maternal health services as needing to be addressed in the absence of a suitable national framework at the time. It was not until 2007 that Norway released its policy on reducing social inequalities in health (Ministry of Health and Care Services, 2007), having accepted in 2003 that there was a need to do so (Strand, Brown, Torgersen, \& Giaever, 2009). Largely defining social inequalities as related to economics, noting that Norway has a stratified society "where the most privileged people, in economic terms, have the best health" (Ministry of Health and Care Services, 2007 p. 5), the policy targets "income, childhood conditions, employment and working environment, health behaviour, health services and social inclusion" (Ministry of Health and Care Services, 2007 p. $6)$.

Norway's commitment to universalism is one in which "social equity is promoted through a distributive social security system" (Strand et al., $2009 \mathrm{p}$. 12). The general needs for the whole population are supplemented by strong social transfer programmes to ensure income inequality in particular does not lead to other inequalities. This is the cornerstone of the health strategy. While not rejecting the universalist principle, the Strategy acknowledges that some targeting is necessary, although not by using a means-testing approach which potentially "stigmatises" people (Ministry of Health and Care Services, 2007 p. 7). How otherwise to identify the most vulnerable groups for specific remedies is not stated, reiterating instead that still the most effective measures to overcome inequalities are through universal provisions. 'Immigrants' are among those groups identified as potentially vulnerable, showing higher levels of health concerns such as mental health issues, and specific diseases such as hepatitis, malaria and tuberculosis. Maternal health is also identified as potentially cause for concern, but that section concludes 
by stating "Further studies need to be undertaken to clarify socioeconomic factors and health among immigrants in Norway" (Ministry of Health and Care Services, 2007 p. 28). Although being an immigrant is identified in the Strategy as requiring attention, and so could be considered itself to be a health risk factor, it could be argued that relying on a universalist provision does not satisfactorily address the specific needs of immigrants, and more especially immigrant women and mothers.

While in this context the terms "equity" and "equality" are used interchangeably (Whitehead \& Dahlgren, 2007 p. 4), it is questionable as to whether the Norwegian position on addressing inequalities fully reflects the Rawlsian (Rawls, 1972) concept of 'fairness' in its construction of equity. The Rawlsian principle of interdependence requires that resources and goods are distributed in such a way to ensure that the least advantaged members of society should be the greatest beneficiaries from public resources. Notwithstanding the commitment to attend to specific needs for specific groups, the overall principle that universal provision is the best solution to achieving social equity stands in this Strategy. Universal provision does not guarantee universal access, or that those services are relevant or culturally sensitive.

\section{Fourth Question - the Limitations}

The way by which these problems have been constructed, pointing to Bacchi's (2009) fourth question (Figure 2), illustrates a central issue for a universalist welfare state. If social equity in health is defined using population wide measures founded (largely) on economic assessments, the strategy targets are likely to overlook specific groups in society such as migrants and migrant women who are not defined by their economic status in relation to health. By focusing on the more generally available health services through societally available institutions such as hospitals, GPs and clinics whose mandate is to ensure the services are available to all, there is no guarantee that these services ensure that all people access them. This is the gap that TEGRA sought to fill for migrant women in their need for specific maternal health services. Their additional goal was to encourage social inclusion, an aim that finds expression in the National Strategy in the form of an education-to-work design, believing that economic inequality results in poorer health, and dropping out of education is a precursor to lower income and/or unemployment. This design feature is not an aspect which would readily fit into any of the provisions from health services. 
The AAAQ model from the UN Committee on Economics, Social and Cultural Rights (CESCR), (World Health Organization, 2007) is useful here to identify how well a policy may be assessed as meeting the four interrelated and partially overlapping elements of: Availability, Accessibility, Acceptability and Quality (AAAQ).

While the services to specifically address maternal and child health needs in the National Strategy (Ministry of Health and Care Services, 2007 p. 38) are available, they do not target the specific needs of migrant mothers for their own health care and knowledge. As mentioned above, GPs, hospitals and clinics all provide post-natal care for example and so are available, but their acceptance by non-Norwegian speaking migrant women as well as potentially their knowledge of these services may be questionable. This is not a comment on their quality, rather more one of whether or not these generalised services are those best suited to women who come from cultures which have different maternal health customs and expectations.

\section{Fifth Question - the Effects}

Following her Foucauldian trajectory, Bacchi's (2009) fifth question (Figure 2) enquires much more specifically into the discursive, subjectification and lived effects of the problematisations. The National Strategy (Ministry of Health and Care Services, 2007) is also applicable here, for although it allowed for some targeting to attend to potential inequalities, the discursive subject, in this case, is all women who need to access maternal health services, and that through provision of the universal services, all women may have their needs met. The effects on the subjects themselves is not necessarily one of blame or accusation for not accessing the provided services, but more of blindness to the particulars of their needs - a blindness TEGRA organisers recognised in their decision to target migrant women. Nevertheless, this provision is framed from a mono-cultural and 'white' oriented Norwegian perspective, with the potential consequence that women and their families, especially the men, withdraw from the workshops and presentations. Cultural awareness and responsiveness (Seeleman, Essink-Bot, Stronks, \& Ingleby, 2015) is a necessary extension to the universal principles of service provision for specific groups. This is not only for the specific health outcomes for migrant mothers and their children, but more broadly as part of the larger integration initiative. Acknowledging the needs of these migrant women through policy and enhancing their relationship with a health system that is respectful of their cultures, their integration can be promoted in Norwegian society by way of increased trust and participation in the system. However, the opposite is 
highly likely as well, where their exclusion by disregarding their migrant milieus can lead to their isolation.

Bacchi's WPR framework primarily focuses on policy analysis and the representation of problems in policies. But she also reflects on the "effects of a given policy in terms of "lived life"' where the primary focus is on "the effects of problem representations on the micro-level" (Cort, 2011 p. 29). Some of these effects can be inferred from the possible embarrassment of men to the breastfeeding information sessions, or the use of male interpreters for women's gynaecological health matters. Possibly some participants may be less inclined to attend future courses because of this, so affecting the acceptability of the provisions, but more importantly resulting in both lack of appropriate information about the Norwegian systems and services, as well as potentially missing out on necessary preventive services.

\section{Sixth Question - Opportunities and Challenges}

The final question in Bacchi's WPR framework (2009) (Figure 2), returns the gaze to the institutions and agencies which sustain the representation of the problem, and leads to the mobilisation of resources to effect change. As Goodwin (2011) articulates, this is the point at which there is the possibility of seeing the policy in a new light having uncovered "knowledge that is critically different from the existing system of meaning" (Goodwin, 2011 p. 174). Here targeted or proportionate universalism may be a policy direction of worth. Although noted as having acknowledged the necessity of some targeting, the National Strategy (Ministry of Health and Care Services, 2007), remains committed to the distributive mechanisms of the welfare state in achieving equity. This Strategy built on earlier policy directions, which relied heavily on the role played by municipalities through their health service provisions (Tallarek née Grimm, Helgesen, \& Fosse, 2013). Such a decentralised approach must trust that the overall aim of national policies is both understood and supported at the local level. Oversight is maintained through nonintrusive or directive means, leaving the lesser-acknowledged policy needs either invisible (and so unaddressed) or dependent on local initiatives. TEGRA was one such initiative, but the extent to which similar initiatives and programmes that attend to maternal health provision for migrant women around the country is unknown, leading to asking a question about how equal health services are for a specific population.

Whitehead and Dahlgren (2007 p. 11), define Social Inequities in Health (SIH) as those "fair arrangements that allow equal geographic, economic and 
cultural access to available services for all in equal need of care". Such an articulation neither specifies the 'cultural' aspect, nor includes migration (Castañeda et al., 2015; Davies, Basten, \& Frattini, 2006; International Organisation for Migration, 2017). Arguably, leaving decisions about these provisions to local municipalities could well lead to inequalities in provision and access, to say nothing of the more specific cultural needs. For all the challenges faced by TEGRA and the inadequacies of the programme in certain respects, the municipality of Stavanger has sought to meet its obligations, and more, in women's health. But it might be questioned as to whether leaving these crucial decisions to municipalities is enough to ensure that the principle of universalism is not undermined by the need for targeted services.

The concept of targeted or proportionate universalism may be usefully considered here. Carey and colleagues (2015), constructed a heuristic using subsidiarity principles from reviewing literature on universal and targeted policy frameworks to propose a mechanism for use by national governments to meet their policy objectives. An adaptation of the heuristic is reproduced in Table 1.

Table 1- Proportionate Universalism Heuristic

\begin{tabular}{|c|l|}
\hline $\begin{array}{l}\text { General } \\
\text { universalism }\end{array}$ & $\begin{array}{l}\text { Federal government responsibility: universal protections } \\
\text { for all (e.g. sanitation) }\end{array}$ \\
\hline $\begin{array}{l}\text { Specific } \\
\text { universalism }\end{array}$ & $\begin{array}{l}\text { Federal government responsibility: universal protections } \\
\text { for citizens (e.g. health care, education) }\end{array}$ \\
\hline Positive selectivism & $\begin{array}{l}\text { State government in partnership with other sectors } \\
\text { (community and business): targeted policies and } \\
\text { programmes based on differing levels of need }\end{array}$ \\
\hline Particularism & $\begin{array}{l}\text { Local government responsibility in partnership with other } \\
\text { sectors (community and business) tailored services for } \\
\text { different cultural, ethnic or otherwise differentiated groups }\end{array}$ \\
\hline
\end{tabular}

Adapted from Carey et al (2015 p. 5)

Operating from the imperative that decisions and actions are taken as close as possible to where they are to be implemented (the subsidiarity principle), different levels of government thereby have differing responsibilities. While Norway's arrangements of counties, municipalities and the national government differ from a Federal system, it could be said to have similar locational responsibilities. Hence, the national government sets policy including laws, such as the Health and Care Services and Public Health Act of 2011 , specifying expectations and roles, for example intersectoral cooperation 
(Ringard et al., 2013). Additionally, these laws allocate responsibilities, such as requiring municipalities to monitor health inequalities and ideally employ a local coordinator to advance such coordination (van der Wel, Dahl, \& Bergsli, 2016). Thus, actions to address needs identified in the National Strategy of 2007 (Ministry of Health and Care Services, 2007) were codified in 2011 with directions to municipalities. Concern at national level continued with the release of a White Paper on Public Health in 2015 although as van der Wel (2016) and colleagues note details are lacking as to the specifics required to reduce inequalities.

Rogaland county could represent the Positive Selectivism governance arrangements through allocated roles from the Ministry of Health and Care Services. Dental care providers for instance are a responsibility of Counties rather than municipalities (Ringard et al., 2013). This represents an example of Positive Selectivism, as it is where community and business interests combine, although this remains unexamined in this study.

As the locus closest to the delivery of service, municipalities can enact particularist principles. The Stavanger municipality has a relationship through its clinic system, with TEGRA, having agreed to fund them in 2007. Although the municipality cannot take the credit for the work of TEGRA, especially the choices made as to how programmes should be implemented and offered to migrant women, it has a certain responsibility. This may be that TEGRA's work forms part of its reporting responsibilities in relation to intersectoral collaboration and other expectations.

\section{Conclusion}

The study reported here started because of observations in social work practice that some migrants from non-European countries had little knowledge of and hesitation in accessing maternal health services. A resultant exploratory research project then concerned how well the principles of universalism as a main policy orientation in all Norwegian service provision met the needs of mothers from very different health systems. A question about the policy-practice nexus was formulated to explore the intersections between what services were provided and how they were delivered. Given the then paucity of research in Norway about this issue, a decision was made to examine this nexus through an in-depth observation of a programme operating to provide maternal health services to migrant women in an area which had a large population of migrant women from predominantly nonEuropean countries. Applying a policy analysis framework to this programme 
in its policy setting has enabled some insights into the tensions present between operating a universal system for people who are not native-born Norwegians. Universalism assumes all people are able to equally access the services provided. Within the universalist system, some targeting is implemented in the recognition that certain groups have additional and special needs. The examination of maternal health provision to migrant women has shown that this group was not necessarily an identified group for targeted services at a national level, and that municipalities were awarded the discretion to decide what services should be provided and how. The TEGRA example has shown that despite targeting at the local level, social equity cannot be guaranteed. Although TEGRA is an illustration of progress in addressing inequality in one municipality in Norway, the underpinnings and processes involved in the problem representation at policy level pose limitations to its effectiveness as there remain gaps in culturally responsive and appropriate services which lead to social inequity. The assumption that everyone has equal access under a universalist system, has inadvertently resulted in a degree of ambiguity in the ethos of equity and equality, leading to a questioning of equality within a universal system. In other words, how much inequality of provision in the interests of equity, can a universalist system tolerate? The answer to this question is for another research study, but this study has revealed that in this location and this reported programme, there are gaps in the theoretically equitable healthcare system, through which a fraction of the population, particularly people from migrant backgrounds could fall. Hence, this approach to equity imposes a weakness on the principle of universalism and has the potential to further deepen inequality.

Nonetheless, designed to fill an identified need at a local level, the experience of this programme has the potential to inform policy development and practice at a national level. Drawing on the principle of subsidiarity and the form of particularism as described by Carey et al (2015), amendments to the TEGRA programme in the form of greater cultural responsiveness and understanding could provide some guidance to similar locally based programmes elsewhere in Norway. Equally in the publishing of this analysis, it is likely that other programmes operating independently in other municipalities may have additional and different suggestions for culturally responsive strategies to contribute to a national health policy which seeks to preserve universalism at the same time as ensuring particular groups have their needs met.

To conclude, in addition to offering an essential contribution to understanding migrant maternal health policy in Norway, this exploratory study's greater 
purpose serves to trigger further discussion and research in this increasingly important arena in Norway where the migrant population in on the rise.

\section{Acknowledgements}

First and foremost, I thank my supervisor and mentor Dr. Susan Young for her guidance throughout the many stages involved in producing this work. I also extend my gratitude to all those who enabled this opportunity through their continued support. Furthermore, we both thank the reviewers and editors at the Nordic Journal of Social Research for their valuable feedback, and last but not least the Faculty of Social Sciences at the University of Stavanger for supporting this publication.

\section{Funding}

This article was made possible by funding from the University of Stavanger in Norway

\section{References}

Bacchi, C. (2009). Analysing Policy: What's the problem represented to be? (1 ed.). Pearson Australia: Pearson Higher Education AU.

Bacchi, C. (2012). Why study problematizations? Making politics visible. Open Journal of Political Science, 2(01), 1-8. https://doi.org/10.4236/ojps.2012.21001

Baxter, P., \& Jack, S. (2008). Qualitative Case Study Methodology: Study Design and Implementation for Novice Researchers. The Qualitative Report, 13(4), 544-559. Retrieved from http://nsuworks.nova.edu/tqr/vol13/iss4/2/

Braun, V. (2009). 'The women are doing it for themselves' The Rhetoric of Choice and Agency around Female Genital 'Cosmetic surgery'. Australian Feminist Studies, 24(60), 233-249. https://doi.org/10.1080/08164640902852449

Carey, G., Crammond, B., \& De Leeuw, E. (2015). Towards health equity: a framework for the application of proportionate universalism. International Journal for Equity in Health, 14(1), 81. https://doi.org/10.1186/s12939-015-0207-6

Castañeda, H., Holmes, S. M., Madrigal, D. S., Young, M.-E. D., Beyeler, N., \& Quesada, J. (2015). Immigration as a social determinant of health. Annual review of public health, 36, 375-392.

https://doi.org/10.1146/annurev-publhealth-032013-182419

Cort, P. (2011). TAKING THE COPENHAGEN PROCESS APART- Critical Readings of European Vocational Education and Training Policy. (PhD Dissertation ). Aarhus University, Aarhus, Denmark.

Darj, E., \& Lindmark, G. (2002). Not all women use maternal health services. Language barriers and fear of the examination are common. Lakartidningen, 99(1-2), 41-44.

Davies, A. A., Basten, A., \& Frattini, C. (2006). Migration: a social determinant of the health of migrants. Retrieved from 
http://citeseerx.ist.psu.edu/viewdoc/download?doi=10.1.1.462.6286\&rep=rep1\&t ype $=$ pdf

Dejin-Karlsson, E., \& Östergren, P.-O. (2004). Country of origin, social support and the risk of small for gestational age birth. Scandinavian Journal Of Public Health, 32(6), 442-449. https://doi.org/10.1080/14034940410028172

Esping-Andersen, G. (1996). Welfare states in transition: National adaptations in global economies. London: Sage.

Gjerstad, B., Johannessen, Ø. L., Nødland, S. I., Skeie, G., \& Vedøy, G. (2016). Policies in Municipal Public Services and Migration to Norway. 159-184. Retrieved from www.jstor.org/stable/24919782

Goodwin, S. (2011). Analysing Policy as Discourse: Methodological Advances in Policy Analysis. In L. Markauskaite, P. Freebody, \& J. Irwin (Eds.), Methodological choice and design. Scholarship, policy and practice in social and educational research (pp. 167-180). London: Springer. https://doi.org/10.1007/978-90-4818933-5_15

Helsenorge. (2015). Interpreter in the health services in Norway. Right to an interpreter Retrieved from https://helsenorge.no/other-languages/english/rights/right-to-aninterpreter

Helsesøstre. (2007). Jærstrendene - manges helsekilde Helsesøstre. (1), 1-81. Retrieved from https://www.nsf.no/Content/252225/HELSES_1_07.pdf

International Organisation for Migration. (2017). Social determinants of migrant health. Retrieved from https://www.iom.int/social-determinants-migrant-health

Kangas, O., \& Kvist, J. (2012). Nordic Welfare States. In B. Greve (Ed.), The Routledge Handbook of the Welfare State (pp. 148-160): Routledge Handbooks Online.

Kvamme, E., \& Ytrehus, S. (2015). Barriers to health care access among undocumented migrant women in Norway. Society, Health \& Vulnerability, 6(1), 1-17. https://doi.org/10.3402/shv.v6.28668

Lancaster, K., \& Ritter, A. (2014). Examining the construction and representation of drugs as a policy problem in Australia's National Drug Strategy documents 19852010. International Journal of Drug Policy, 25(1), 81-87. https://doi.org/10.1016/j.drugpo.2013.07.002

Ministry of Health and Care Services. (2007). National strategy to reduce social inequalities in health-Report No. 20 (2006-2007) to the Storting. Retrieved from https://www.regjeringen.no/en/dokumenter/report-no.-20-to-the-storting-20062007/id449531/

Muula, A. S. (2007). Ethical and Practical Consideration of Women Choosing Cesarean Section Deliveries without "Medical Indication" in Developing Countries. Croatian medical journal, 48(1), 94-102. Retrieved from http://www.ncbi.nlm.nih.gov/pmc/articles/PMC2080500/

Navarro, V., \& Shi, L. (2001). The political context of social inequalities and health. Social science \& medicine, 52(3), 481-491. Retrieved from https://doi.org/10.1016/S0277-9536(00)00197-0

https://doi.org/10.1016/S0277-9536(00)00197-0

Nørredam, M., \& Krasnik, A. (2011). Migrants' access to health services. In B. Rechel, P. Mladovsky, W. Devillé, B. Rijks, R. Petrova-Benedict, \& M. McKee (Eds.), Migration and health in the European Union (pp. 67-78): Open University Press, Maidenhead.

Norwegian Directorate for Health. (n.d). Gruppekonsultasjoner: Helsestasjonen bør gi alle foreldre tilbud om å delta i gruppekonsultasjoner. Retrieved from 
https://helsedirektoratet.no/retningslinjer/helsestasjons-og-

skolehelsetjenesten/seksjon?Tittel=helsestasjon-05-ar-

3952\#gruppekonsultasjoner:-helsestasjonen-bør-gi-alle-foreldre-tilbud-om-å-

delta-i-gruppekonsultasjoner

Norwegian Ministries. (2008). Action Plan for Combating Female Genital Mutilation. Retrieved from https://www.regjeringen.no/globalassets/upload/hod/dokumenterfha/kjonnslemlestelse/handlingsplan_kjonnsl_eng_nett.pdf

Ny, P. (2007). Swedish Maternal Health Care In a Multiethnic Society - Including The Fathers. (Doctoral Dissertation ). Malmo"University, Sweden.

Pierson, C., \& Leimgruber, M. (2010). Intellectual Roots. In F. G. Castles, S. Leibfried, J. Lewis, H. Obinger, \& C. Pierson (Eds.), The Oxford Handbook of the Welfare State (pp. 1-15): Oxford University Press. https://doi.org/10.1093/oxfordhb/9780199579396.003.0003

Rawls, J. (1972). A theory of justice. Oxford: Clarendon Press.

Rechel, B., Mladovsky, P., Devillé, W., Rijks, B., Petrova-Benedict, R., \& McKee, M. (2011). The future of migrant health in Europe. In B. Rechel, P. Mladovsky, W. Devillé, B. Rijks, R. Petrova-Benedict, \& M. McKee (Eds.), Migration and health in the European Union (pp. 245-250): Open University Press, Maidenhead.

Reeske, A., \& Razum, O. (2011). Maternal and child health-from conception to first birthday. In B. Rechel, P. Mladovsky, W. Devillé, B. Rijks, R. Petrova-Benedict, \& M. McKee (Eds.), Migration and health in the European Union (pp. 139-154): Open University Press, Maidenhead.

Regjeringen. (2017). NOU 2017: 2 Integration and trust- Long-term onsequences of high immigration - Translation of chapter 1.1.: Regjeringen.no Retrieved from https://www.regjeringen.no/en/dokumenter/nou-2017-2/id2536701/

Ricoeur, P. (1971). The model of the text: meaningful action considered as text. Social Research, 38, 529-562.

Ringard, A., Sagan, N., Saunes, I. S., \& Lindahl, A. K. (2013). Norway: Health system review. Health Systems in Transition, 15(8), 1-162.

Seeleman, C., Essink-Bot, M.-L., Stronks, K., \& Ingleby, D. (2015). How should health service organizations respond to diversity? A content analysis of six approaches. BMC health services research, 15, 510-510. https://doi.org/10.1186/s12913-0151159-7

SSB. (2017a). 07111: Immigrants and Norwegian-born to immigrant parents, by sex and age. Groups of country background. Retrieved from https://www.ssb.no/en/statbank/table/07111/

SSB. (2017b). Immigrants and Norwegian-born to immigrant parents, 1 January 2017. Retrieved from https://www.ssb.no/en/befolkning/statistikker/innvbef

SSB. (2017c). Key figures for the population. Retrieved from https://www.ssb.no/en/befolkning/nokkeltall/population

Stavanger Kommune. (2016a). TEGRA, svangerskapskurs og barselgruppe. Retrieved from http://www.stavanger.kommune.no/no/Tilbud-tjenester-og-skjema/Barn-ogfamilie/Helsestasjon/Gruppetilbud1/TEGRA/

Stavanger Kommune. (2016b). TEGRA, svangerskapskurs og barselgruppe. http://www.stavanger.kommune.no/no/Tilbud-tjenester-og-skjema/Barn-ogfamilie/Helsestasjon/Gruppetilbud1/TEGRA/ 
Stevens, E. E., Patrick, T. E., \& Pickler, R. (2009). A History of Infant Feeding. The Journal of Perinatal Education, 18(2), 32-39. https://doi.org/10.1624/105812409X426314

Strand, M., Brown, C., Torgersen, T. P., \& Giaever, O. (2009). Setting the political agenda to tackle health inequity in Norway: WHO Regional Office for Europe.

Sykepleierforbund, N. (2014). NSF Lokalen Retrieved from https://www.nsf.no/visartikkel/2205224/264607/NSF-Lokalen----oktober-2014

Tallarek née Grimm, M. J., Helgesen, M. K., \& Fosse, E. (2013). Reducing social inequities in health in Norway: Concerted action at state and local levels? Health policy, 113(3), 228-235. https://doi.org/10.1016/j.healthpol.2013.09.019

Tronstad, K., Nygaard, M. O., \& Bask, M. (2018). Accumulation of welfare problems among immigrants in Norway. In: Norwegian Institute for Urban and Regional Research (NIBR).

van der Wel, K. A., Dahl, E., \& Bergsli, H. (2016). The Norwegian policy to reduce health inequalities: key challenges. Nordisk välfärdsforskning, 1(01), 19-29. https://doi.org/10.18261/issn.2464-4161-2016-01-03

Whitehead, M., \& Dahlgren, G. (2007). Concepts and principles for tackling social inequities in health: Levelling up Part 1. WHO Collaborating Centre for Policy Research on Social Determinants of Health University of Liverpool: WHO Regional Office for Europe

World Health Organization. (2007). The Right to Health- JOINT FACT SHEET $\mathrm{WHO} / \mathrm{OHCHR} / 323 . \quad 1-2 . \quad$ Retrieved from http://www.who.int/mediacentre/factsheets/fs323 en.pdf 